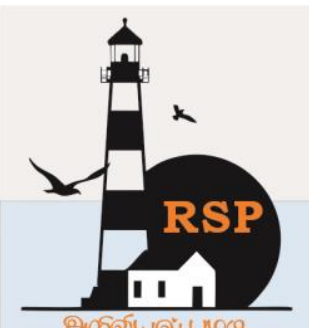

INTERNATIONAL RESEARCH JOURNAL ON ADVANCED SCIENCE HUB

-ISSN : $2582-4376$ Open Access

RSP SCIENCE HUB

(The Hub of Research Ideas)

Available online at www.rspsciencehub.com

\title{
Optimization of cutting parameters during Turning of AISI d3 steel using dry and Lubrication condition
}

N.Rajiv Kumar ${ }^{1}$, P.Umar Ahamed ${ }^{2}$, A.Muhammad saleh ${ }^{3}$

${ }^{1}$ Research scholar, Department of Mechanical Engineering, Sri Krishna College of Engineering and Technology, Coimbatore, Tamil Nadu, India.

${ }^{2,3}$ Assistant Professor, Department of Mechanical Engineering, Mohamed sathak Engineering College

Ramanathapuram, Tamil Nadu, India.

\begin{abstract}
The objective of this paper is focused on turning of AISI D3 Steel using coated cemented carbide tool cutting inserts. The experiments were performed on a KIROLOSKAR model center lathe using three input cutting parameters, cutting speed, feed and depth of cut. Hardened steels are most widely used in multifarious industrial applications like tool design and mould design. The output responses measured were surface roughness (Ra), Interface temperature and material removal rate (MRR). In present study, the Taguchi technique has been used to optimize the controllable process parameters for AISI D3 cold work turning tools then the interaction effects of various hard turning parameters on each response were also studied using analysis of variance (ANOVA) and interaction plots. Further a regression is modelled as a function of cutting parameters to predict values for surface roughness in comparison with experimental values within reasonable limits. Based on the main effects plots and signal to noise ratio (S/N) obtained through Taguchi's approach, were used to relate the optimum level for surface roughness chosen from the considered there levels of cutting parameters.
\end{abstract}

Keywords: AISID3 steel, ANOVA, Taguchi, MRR etc.

\section{Introduction}

The important goal in the modern industries is to manufacture the product with lower cost and with high quality in short span of time. There are two main practical problems that engineers face in a manufacturing process, the first is to determine the values of process parameters that will yield the desire product quality (meet technical specifications) and the second is to maximize manufacturing system performance using the available resources. The challenge of modern machining industry is mainly focused on achievement of high quality, in terms of work piece dimensional accuracy, surface finish ,high production rate, less wear on the cutting tools economy of machining in terms of cost saving and increase the performance of the product with reduced environmental impact. Increase in productivity and the quality of the machined parts are the main challenges of metal based industry. There has been increased interest in monitoring all aspects of machining process. Surface finish is an important parameter in manufacturing engineering it is a characteristic that could influence the performance of mechanical parts and the production costs. Surface roughness has become the most significant technical requirement and is an index of product quality in order to improve the tribological properties, fatigue strength, corrosion resistance and aesthetic appeal of the product reasonably good surface finish is required. Now a day's manufacturing industries specially concerned to dimensional accuracy and surface finish. This work reviews in details the literature 


\section{www.rspsciencehub.com}

for a better understanding of the problem discussed in this area. T. Tamizharasan, J. Kingston Barnabas, "optimization of parameters in hard dry turning using doe, de and pso". The objective of this investigation is to obtain an optimal setting of product and process parameters in turning for minimizing the flank wear of tool and for improving the surface finish of the manufactured Component . HM Somasekhara, Lakshamana Swami, "optimizing surface roughness in turning operation using Taguchi method and ANOVA" ,the objective of this paper is to obtain a optimal setting of turning parameters ( speed, feed and depth $\mathrm{f}$ cut) which results in an optimum value of surface roughness while machining A1 6351 T6 alloy using uncoated carbide inserts by applying genetic algorithm . [1-4] Hari Singh, Pradeep, optimizing cutting force for turned parts for Taguchi's parameters design approach, the objective of this paper is to obtain the optimum setting of turning process parameters cutting speed, feed and depth of cut resulting in an optimum value of cutting force while machining En 24 alloy steel with Tic coated carbide inserts. Varaprasad Bhemuni, SrinivasaRao Chelamalasetti, Siva Prasad Kondapalli, "Effect of Machining Parameters on Tool Wear and Nodal Temperature in Hard Turning of AISI D3 Steel", this paper attempts has been made to develop a model and predict the tool wear and nodal temperature of hard turned AISI D3 hardened steel using Response Surface Methodology (RSM). J.S. Durejaa, Rupinder Singha\&Manpreet S. Bhattib , “ Optimizing flank wear and surface roughness during hard turning of AISI D3 steel" by Taguchi and RSM methodsthis paper investigate tool wear (flank wear) and surface roughness during finish hard turning of AISI D3 steel (58HRC) with coated carbide (TiSiN-TiAlNcoated) cutting tool. Taguchi L9 (3)3 orthogonal array has been applied for experimental design. $\mathrm{S} / \mathrm{N}$ ratio and ANOVA analyses were performed to identify significant parameters influencing tool wear and surface roughness. Esmaeil Soltani, HesamShahali an investigation of surface roughness and main cutting force during the hard turning of AISI d3 tool steel using ceramic tools, this paper depicts The combined effects of four machining parameters, including cutting speed, feed rate, hardness and tool corner radius were investigated
Volume 02 Issue 04 April 2020

based on two performance characteristics involving surface roughness and main cutting force. Central composite design (CCD) was applied as experimental design. R.K.Suresh, P.Venkataramaiah, G.Krishnaiah depicts that approach basedon Grey relational analysis and Desirability function analysis for optimizing the process parameters during turning of AISI 8620 alloy steel with CVD coated tool with multiple performance characteristics. Experimentation were carried out on a CNC lathe using L9 orthogonal array based on Taguchi design of experiments. The optimal turning parameters are determined by composite desirability index and grey relational grade. Analysis of variance (ANOVA) is used to determine the influence of parameters which significantly affect the responses. The objectives of present work are: Conducting experimentation by application of orthogonal array for design of experiments and implementing Taguchi method for finding the effect of cutting parameters To develop a Regression model using MINITAB 16 software and compare with the experimental roughness values.[5-9].

\section{Experimental Procedure}

An engine lathe was used for conducting the experiments. AISI D3 a cold work steel was used as the work material and CVD coated cemented carbide was used as the cutting tool. The average surface roughness on the work piece was measured using SV-C4500 surface roughness measuring instrument. The experimentation of this work was based on Taguchi's design of experiments have to be carried out when the number of the process parameters increases. In this work, three cutting parameters namely, spindle speed, depth of cut and feed rate were considered for experimentation. Accordingly there are three input parameters and for each parameter three levels were assumed. For three factors, three level experiments, Taguchi had specified L9 orthogonal array experimentation was recorded and further analyzed. Table 1 shows the parameters and their levels considered for experiment. The tests were carried for a work piece bar of $40 \mathrm{~mm}$ Diameter and $70 \mathrm{~mm}$ length in a KIROLOSKAR model center lathe using three input cutting parameters, cutting speed, feed and depth of cut. CVD coated cemented carbide for the different alloying elements of AISI D3 a cold work steel are shown 
www.rspsciencehub.com

in Table $2 \& 3$. The various Mechanical properties of AISI D3 cold work steel are shown in Table 4. The various properties of AISI D3 cold work steel are shown in Table 5 The cutting parameters of
Volume 02 Issue 04 April 2020

machining of AISI D3 cold work steel are cutting speed, depth of cut and feed are taken as shown in table1.The Physical Properties of AISI D3 Cold Work Steel is shown in table 5.

Table 1: The process parameters and their levels

\begin{tabular}{|l|c|c|c|}
\hline \multicolumn{1}{|c|}{ Cutting Parameters } & Level 1 & Level 2 & Level 3 \\
\hline Spindle Speed(rpm) & 450 & 710 & 1120 \\
\hline Feed(mm/rev) & 0.05 & 0.071 & 0.09 \\
\hline Depth of cut(mm) & 1.0 & 1.5 & 2.0 \\
\hline
\end{tabular}

Table 2: Chemical composition of AISI D3 cold work Steel

\begin{tabular}{|l|c|c|c|c|c|c|c|c|c|c|}
\hline Elements & $\mathbf{C}$ & $\mathbf{S i}$ & $\mathbf{M n}$ & $\mathbf{C r}$ & $\mathbf{P}$ & $\mathbf{S}$ & $\mathbf{N i}$ & $\mathbf{M}$ & $\mathbf{A l}$ & $\mathbf{B}$ \\
\hline$\%$ & 2.179 & 0.511 & 0.511 & 12.634 & 0.027 & 0.021 & 0.050 & 0.178 & 0.042 & 0.065 \\
\hline
\end{tabular}

Table 3: CVD- coating constituents

\begin{tabular}{|l|l|l|}
\hline Type of constituent & Acronym & Properties \\
\hline $\mathrm{MT}-\mathrm{Ti}(\mathrm{C}, \mathrm{N})$ & $\begin{array}{l}\text { modern titanium carbonitride } \\
\text { coatings }\end{array}$ & $\begin{array}{l}\text { Its hardness provides abrasive wear } \\
\text { resistance, resulting in reduced flank wear }\end{array}$ \\
\hline $\mathrm{CVD}-\mathrm{Al}_{2} \mathrm{O}_{3}$ & Alumina coatings $\left(\mathrm{Al}_{2} \mathrm{O}_{3}\right)$ & $\begin{array}{l}\text { Chemically inert with low thermal } \\
\text { conductivity, making it resistant to crater } \\
\text { wear. It also acts as a thermal barrier to } \\
\text { improve plastic deformation resistance }\end{array}$ \\
\hline CVD-TiN & titanium carbide coating (TiC) & $\begin{array}{l}\text { Improves wear resistance and is used for } \\
\text { wear detection }\end{array}$ \\
\hline
\end{tabular}

Table 4: Mechanical Properties Of AISI D3 Cold work Steel

\begin{tabular}{|l|l|l|}
\hline \multicolumn{1}{|c|}{ Properties } & \multicolumn{1}{|c|}{ Metric } & \multicolumn{1}{c|}{ Imperial } \\
\hline Izod impact un-notched & $28.0 \mathrm{~J}$ & $20.7 \mathrm{ft}-\mathrm{lb}$ \\
\hline Poisson's ratio & $0.27-0.30$ & $0.27-0.30$ \\
\hline Elastic modulus & $190-210 \mathrm{GPa}$ & $27557-30457 \mathrm{ksi}$ \\
\hline
\end{tabular}


Table 5: Physical Properties of AISI D3 Cold Work Steel

\begin{tabular}{|l|l|l|}
\hline Properties & Metric & Imperial \\
\hline Density & $7.7 \times 1000 \mathrm{~kg} / \mathrm{m} 3$ & $0.278 \mathrm{lb} . / \mathrm{in} 3$ \\
\hline Melting point & $1421^{\circ} \mathrm{C}$ & $2590^{\circ} \mathrm{F}$ \\
\hline
\end{tabular}

The design of experiments (DOE) is an effective approach to optimize the throughout in various manufacturing -related processes. The DOE had been implemented to select minimum

\subsection{Experimental details and specification}

surface roughness of cylindrical work piece and cutting force is investigated the L9 orthogonal arrays was selected for this study.

$\begin{array}{lcc}\text { Machine tool } & : & \text { Kiroloskar Centre Lathe } \\ \text { Work material } & : & \text { nAISI D3 cold Working Steel } \\ \text { Cutting tool } & : & \text { CVD cemented carbide tool } \\ \text { Available cutting parameters and ranges } & \\ \text { Speed V (rpm) } & : & 450,710, \text { and } 1120 \\ \text { Feed rate }(\mathrm{mm} / \mathrm{rev}) & : & 0.05,0.071,0.09, \\ \text { Depth of cut }(\mathrm{mm}) & : & 1.0,1.5,2.0 \\ \text { Cutting conditions: Dry cutting \& minimum quantity LUBRICATION }\end{array}$

\section{DESIGN OF EXPERIMENT}

In order to achieve the desired aim, the investigations were planned to be carried out in the following steps.

1. Identifying the machining parameters

2. Selection of useful limits of the cutting parameters namely speed, feed and depth of cut.

3. Developing the design matrix

4. Conducting the experiment as per the Taguchi design matrix

5. Testing the significance of regression coefficient and arriving at the final form of the mathematical models.

6. Presenting the main effects and significance interactions between different in the graphical forms

7. Analysis of results and conclusions

A design of experiment is a structured, organized method for determining the relationship between factors affecting a process and the output of that process

1. Conducting and analyzing controlled tests to evaluate the factors that control the value of parameter or a group of parameters

2. Design of experiments refers to experimental methods used to quantify indeterminist measurements of factors and interactions between factors statistically through observance of forced changes methodically as directed by mathematically systematic tables

Design of experiment techniques

1. Factorial designs

2. Response surface methodology

3. Mixture design

4. Taguchi design

Among those we had selected taguchi design for optimizing surface roughness in turning operation.

\section{RESULTS AND DISCUSSIONS}

Taguchi's emphasis on minimizing deviation from target led him to develop measures of process output that incorporate both the location of the output as well as the variation. These measures are called Signal to noise ratio. The Signal to Noise ratio provides the measure of the impact of noise factors and performance. The larger $\mathrm{S} / \mathrm{N}$, the more robust the product is against noise. Calculation of $\mathrm{S} / \mathrm{N}$ ratio depends on experimental objective AISI D3 cold working steel and CVD coated cemented carbide tool. For the corresponding response surface roughness the signal to noise ratio and means are calculated by using the formula which is the lower the better 
www.rspsciencehub.com

value. The result obtained is tabulated as shown in the table 6.From the table 6 Depth of cut has the higher value of 14.7285 than speed and feed.so, Depth of cut affects the surface roughness. From
Volume 02 Issue 04 April 2020

the table 7 depth of cut has the higher value of 9.0473 than speed and feed.so, Depth of cut affects the surface roughness. The Response table for signal to noise ratio (Dry) is shown in table 8 . to noise ratio (LUBRICATION)

Table 6 : Response table for signal to noise ratio (LUBRICATION)

\begin{tabular}{|c|c|c|c|}
\hline Level & Speed (rpm) & Feed (mm/rev) & Depth of cut(mm) \\
\hline 1 & 0.9006 & -1.4446 & 4.4767 \\
\hline 2 & -0.4591 & -0.9194 & 2.8305 \\
\hline 3 & -3.3862 & -0.5807 & -10.2518 \\
\hline 4 & 4.2868 & 0.8639 & 14.7285 \\
\hline Rank & 2 & 3 & 1 \\
\hline
\end{tabular}

Table 7: Response table for signal to noise ratio (Dry)

\begin{tabular}{|c|c|c|c|}
\hline Level & Speed (rpm) & Feed (mm/rev) & Depth of cut (mm) \\
\hline 1 & 2.100 & 0.3794 & 4.4258 \\
\hline 2 & 0.9856 & -0.9396 & 2.3281 \\
\hline 3 & -0.9531 & 2.6927 & -4.6214 \\
\hline 4 & 3.0530 & 3.6322 & 9.0473 \\
\hline Rank & 3 & 2 & 1 \\
\hline
\end{tabular}

Table 8: Response Table for Means (LUBRICATION)

\begin{tabular}{|c|c|c|c|}
\hline Level & Speed (rpm) & Feed (mm/rev) & Depth of cut (mm) \\
\hline 1 & 1.0567 & 2.2433 & 0.6000 \\
\hline 2 & 1.4667 & 1.5000 & 0.7400 \\
\hline 3 & 2.4000 & 1.1800 & 3.5833 \\
\hline Delta & 1.3433 & 1.0633 & 2.9833 \\
\hline Rank & 3 & 1 & 2 \\
\hline
\end{tabular}

Table 9 : Response Table for Means (Dry)

\begin{tabular}{|c|c|c|c|}
\hline Level & Speed $(\mathbf{r p m})$ & Feed $(\mathbf{m m} / \mathbf{r e v})$ & Depth of cut $(\mathbf{m m})$ \\
\hline 1 & 0.8633 & 1.5200 & 0.6167 \\
\hline 2 & 0.9933 & 1.2000 & 0.8267 \\
\hline 3 & 1.6033 & 0.7400 & 2.0167 \\
\hline Delta & 0.7400 & 0.7800 & 1.4000 \\
\hline Rank & 3 & 2 & 1 \\
\hline
\end{tabular}


The table $8 \& 9$ indicates the Response table means of lubrication and Dry condition. The table 10 shows the linear model of process parameters, Analysis of variance is concerned with determining whether variances in two or more populations are significantly different. The experimental results were analysed with the analysis of variance (ANOVA), which is used to investigate design parameters significantly affect the quality characteristic. This is too accomplished by separating the total variability of the $\mathrm{S} / \mathrm{N}$ ratio, which is measured by the sum of squared deviations from total mean $\mathrm{S} / \mathrm{N}$ ratio, into contributions by each of the design parameters and the error. The result of ANOVA on the surface roughness $(\mathrm{Ra})$ is shown in the following Table $11 \& 12$. Ra versus speed (s), feed (f) and depth of cut (d) and interactions of parameters is also allowed to determine the effect of any two cutting parameters where as other parameter is maintained constant throughout the design of experiment.

Table 10: Linear Model

\begin{tabular}{|c|c|c|c|}
\hline Factor & Type & levels & Values \\
\hline Spindle Speed(s) & Fixed & 3 & $1,2,3$ \\
\hline Feed (f) & Fixed & 3 & $1,2,3$ \\
\hline Depth of cut (d) & Fixed & 3 & $1,2,3$ \\
\hline
\end{tabular}

Table 11: Percentage contribution table (LUBRICATION)

\begin{tabular}{|c|c|c|c|c|c|}
\hline Source & $\begin{array}{c}\text { Degrees of } \\
\text { freedom }\end{array}$ & $\begin{array}{c}\text { sum of } \\
\text { squares }\end{array}$ & $\begin{array}{c}\text { Mean of } \\
\text { squares }\end{array}$ & F-Ratio & \% contribution \\
\hline Speed & 2 & 2.8408 & 1.4204 & 1.0628 & 11.6927 \\
\hline Feed & 2 & 1.7808 & 0.8904 & 0.66624 & 7.3298 \\
\hline Depth of cut & 2 & 17.008 & 8.005 & 6.3604 & 70 \\
\hline Error & 2 & 2.6729 & 1.33645 & & 11 \\
\hline Total & 8 & 24.3025 & & & \\
\hline
\end{tabular}


Table 12: Percentage contribution table (Dry)

\begin{tabular}{|c|c|c|c|c|c|}
\hline Source & $\begin{array}{c}\text { Degrees of } \\
\text { freedom }\end{array}$ & $\begin{array}{c}\text { sum of } \\
\text { squares }\end{array}$ & $\begin{array}{c}\text { Mean of } \\
\text { squares }\end{array}$ & F-Ratio & $\begin{array}{c}\text { \% } \\
\text { contribution }\end{array}$ \\
\hline Speed & 2 & 0.9364 & 0.4682 & 0.65 & 12.11 \\
\hline Feed & 2 & 1.9355 & 0.9677 & 1.3479 & 25.04 \\
\hline $\begin{array}{c}\text { Depth of cut } \\
\text { (mm) }\end{array}$ & 2 & 3.42 & 1.71 & 2.3819 & 44.25 \\
\hline Error & 2 & 1.4359 & 0.7179 & & 18.58 \\
\hline Total & 8 & 7.7278 & & & 100 \\
\hline
\end{tabular}

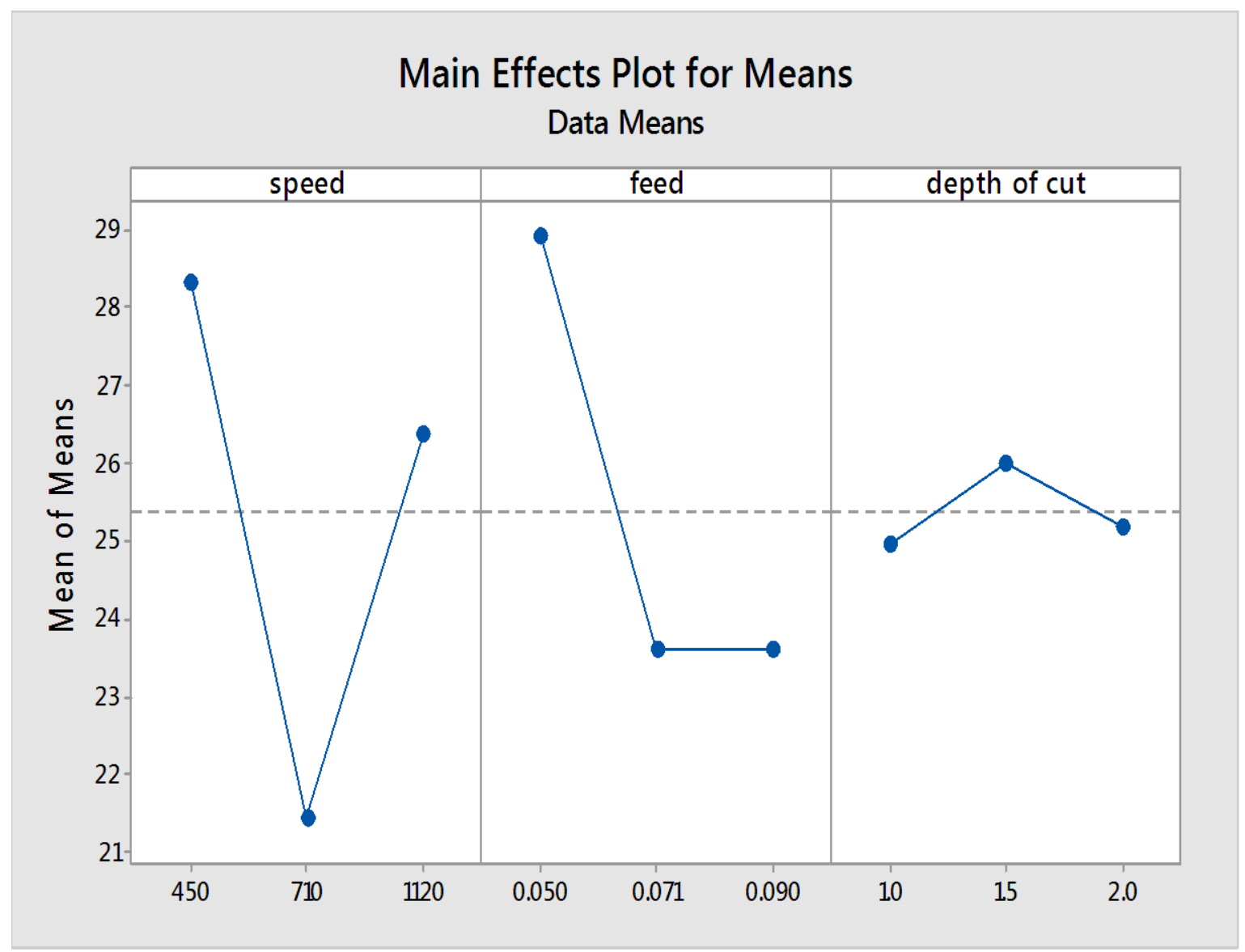

Fig.1. Main Effects Plot for Means (LUBRICATION) 


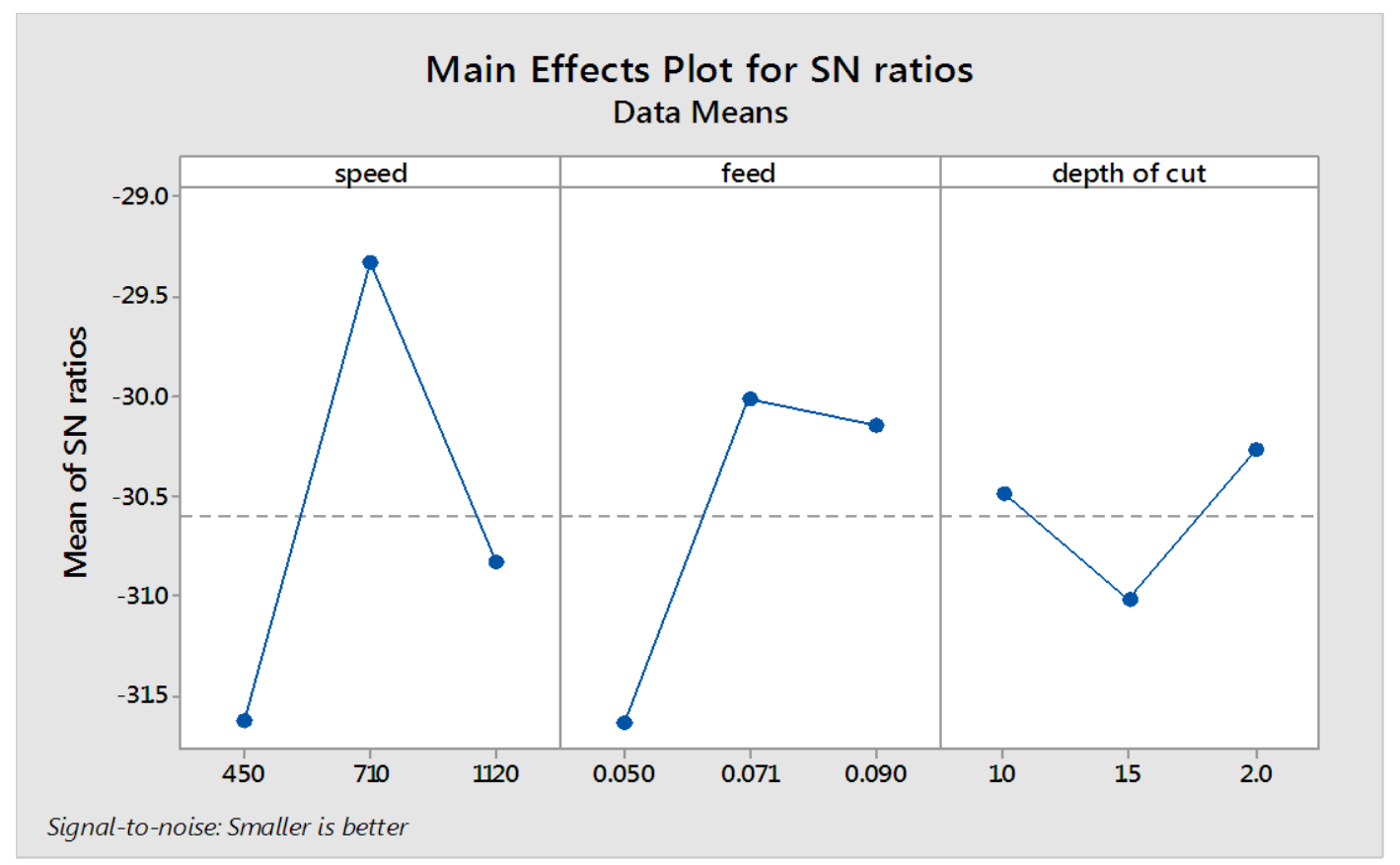

Fig.2. Main Effects Plot for S/N ratios (LUBRICATION)

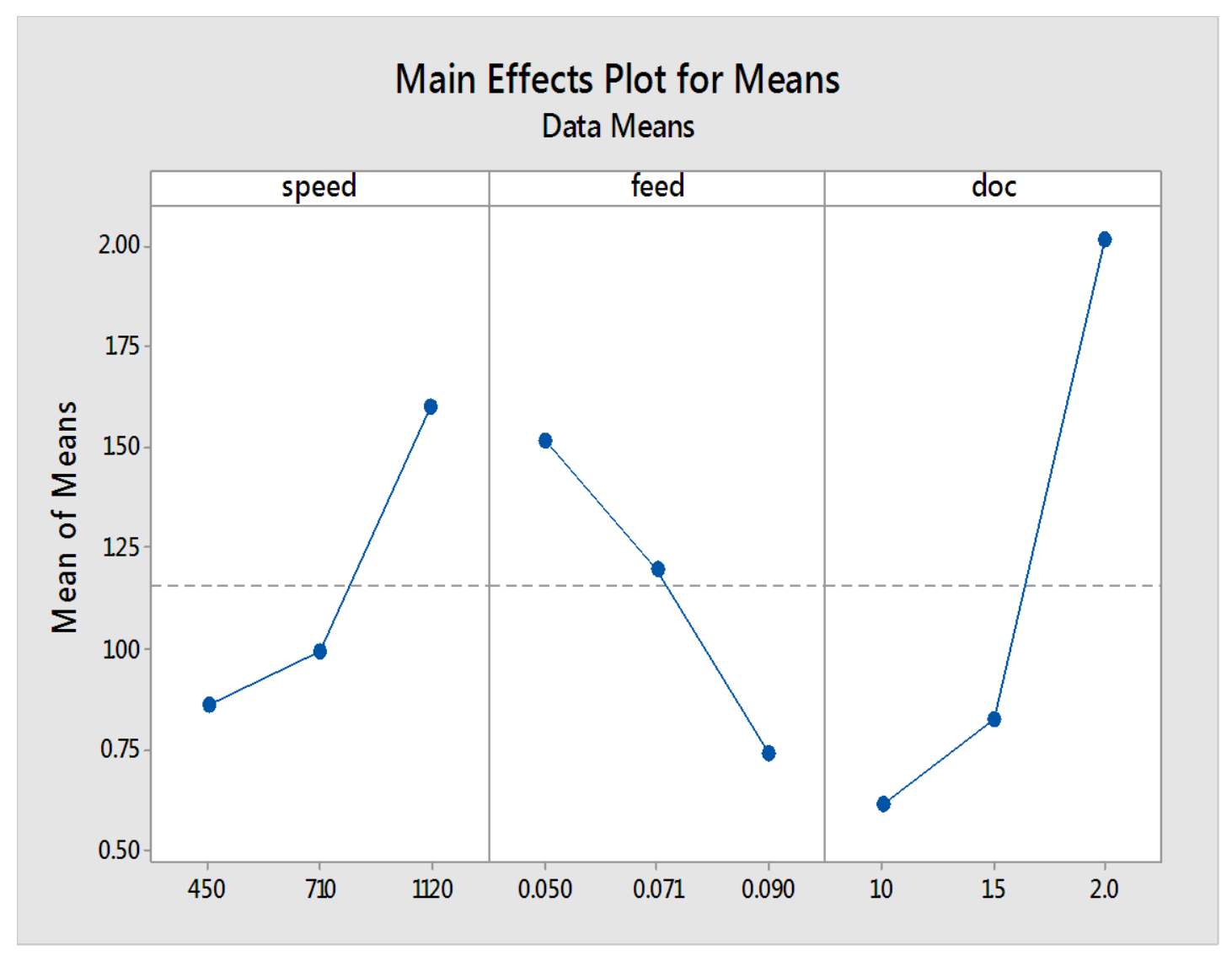

Fig.3.: Main Effects Plot for Means (Dry) 


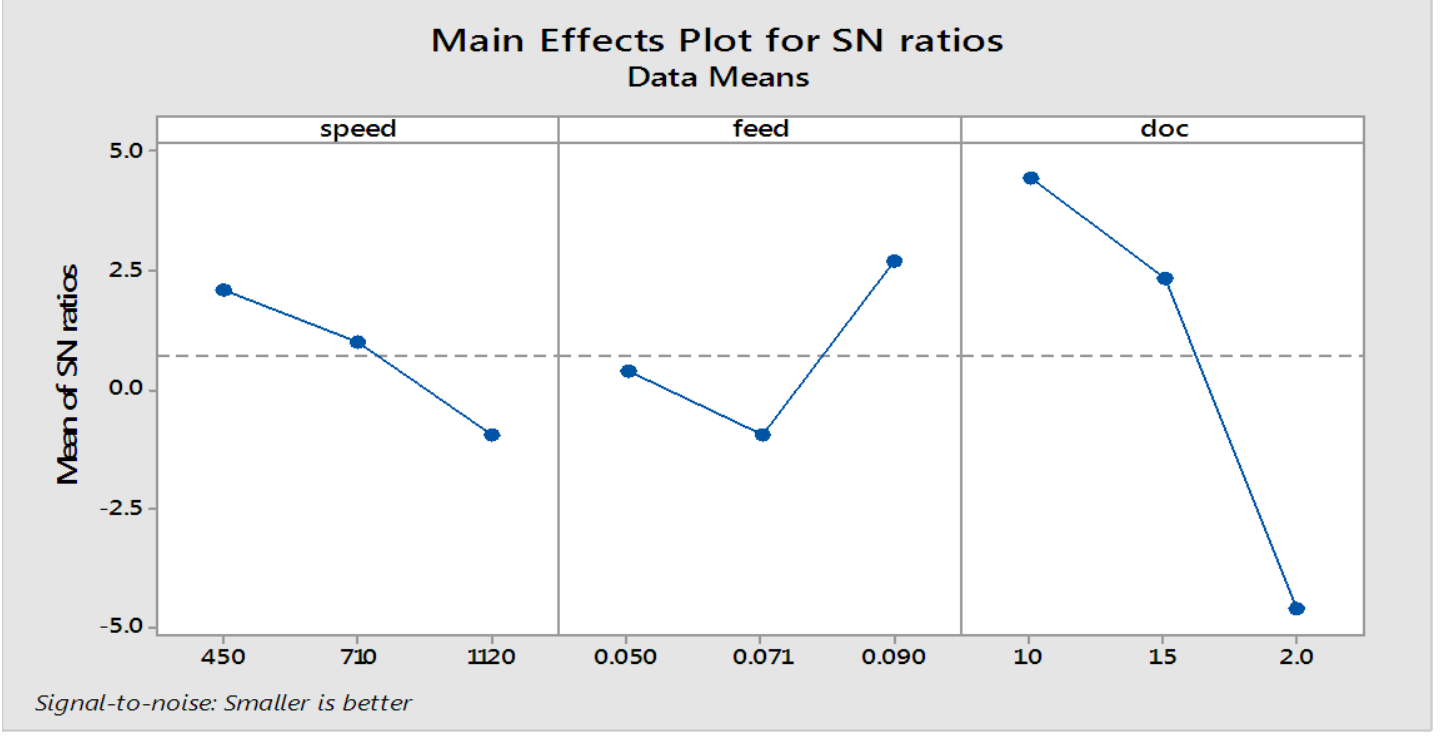

Fig.4. Main Effects Plot for S/N ratios (Dry)

From the Fig 1 main effect plots for Means vs Speed, Feed, depth of cut. On this Speed (450), feed (0.050), Depth of cut (1.5) the surface roughness will be minimum. The Fig. 2 is drawn by the mean of signal to noise ratio vs Speed, Feed, Depth of cut. The signal to noise ratio should be minimum. So, in this speed(450),Feed(0.050), Depth of cut (1.5) the surface roughness will be minimum.The Fig.3. shows the mean of means vs speed, feed, depth of cut in dry condition. On this speed(1120), feed(0.050), depth of cut(2.0) the surface roughness will be minimum. The Fig.4. Shown Main Effects Plot for S/N ratios (Dry). The Table $13 \& 14$ shows the predicted and experimental roughness at lubrication and dry conditions.

Table 13: Response table for predicted and experimental roughness (LUBRICATION)

\begin{tabular}{|c|c|c|c|c|}
\hline Speed(rpm) & Feed(mm/rev) & $\begin{array}{c}\text { Depth of } \\
\mathbf{c u t}(\mathbf{m m})\end{array}$ & $\begin{array}{c}\text { Exp } \\
\mathbf{R a}(\boldsymbol{\mu m})\end{array}$ & $\begin{array}{c}\text { Predicted } \\
\mathbf{R a}(\boldsymbol{\mu m})\end{array}$ \\
\hline 450 & 0.05 & 1.0 & 0.53 & 0.39 \\
\hline 450 & 0.071 & 1.5 & 0.72 & 0.95 \\
\hline 450 & 0.09 & 2 & 1.92 & 1.78 \\
\hline 710 & 0.05 & 1.5 & 0.55 & 1.29 \\
\hline 710 & 0.071 & 2 & 3.18 & 2.37 \\
\hline 710 & 0.09 & 1 & 0.67 & 0.45 \\
\hline 1120 & 0.05 & 2 & 5.65 & 3.22 \\
\hline 1120 & 0.071 & 1. & 0.60 & 0.65 \\
\hline 1120 & 0.09 & 1.5 & 0.95 & 1.49 \\
\hline
\end{tabular}


Table 14: Response table for predicted and experimental roughness (Dry)

\begin{tabular}{|c|c|c|c|c|}
\hline Speed(rpm) & Feed(mm/rev) & Depth of cut(mm) & Exp Ra( $\boldsymbol{\mu m})$ & Predicted Ra( $\boldsymbol{\mu m})$ \\
\hline 450 & 0.05 & 1.0 & 0.44 & 0.51 \\
\hline 450 & 0.071 & 1.5 & 1.31 & 0.8 \\
\hline 450 & 0.09 & 2 & 0.84 & 1.10 \\
\hline 710 & 0.05 & 1.5 & 0.56 & 1.09 \\
\hline 710 & 0.071 & 2 & 1.65 & 1.44 \\
\hline 710 & 0.09 & 1 & 0.77 & 0.48 \\
\hline 1120 & 0.05 & 2 & 3.56 & 1.97 \\
\hline 1120 & 0.071 & 1. & 0.64 & 0.63 \\
\hline 1120 & 0.09 & 1.5 & 0.61 & 1 \\
\hline
\end{tabular}

4.1. Signal Factors Influence On RA for the tool CVD on AISI D3 Cold Working Steel

The plots consisting of mean effects for S/N Ratio and interaction plot for means, smalleris-better ( $\mathrm{S} / \mathrm{N}$ Ratio) is selected as an objective of performance characteristics for minimizing the target Ra of signal factors speed, feed and depth of cut. Among the machining parameters Feed is the most influence parameter. For surface roughness (Ra).The table $15 \& 16$ shows the optimized results for AISI D3 on CVD tool at Lubrication and dry conditions for machining process.

Table 15: Optimized table obtained for AISI D3 on CVD tool (LUBRICATION)

\begin{tabular}{|c|c|c|c|}
\hline Control factors & Speed(s)rpm & Feed (f) mm/rev & $\begin{array}{c}\text { Depth of cut(d) } \\
\mathrm{mm}\end{array}$ \\
\hline Surface roughness $(\mathrm{Ra}) \mu \mathrm{m}$ & 450 & 0.09 & 1.0 \\
\hline
\end{tabular}

Table 16: Optimized table obtained for AISI D3 on CVD tool (Dry)

\begin{tabular}{|c|c|c|c|}
\hline Control factors & Speed(s)rpm & Feed (f) mm/rev & $\begin{array}{c}\text { Depth of cut(d) } \\
\mathrm{mm}\end{array}$ \\
\hline Surface roughness $(\mathrm{Ra}) \mu \mathrm{m}$ & 450 & 0.09 & 1.0 \\
\hline
\end{tabular}




\section{CONCLUSION}

The analyzed results from turning AISI D3 Cold Working steel with CVD coated cemented carbide inserts revealed the following conclusions.

$>$ Taguchi is an efficient and systematical methodology for optimizing turning parameters and can be utilized rather than engineering judgment.

$>$ It is observed that feed is the most influential controlling factor on surface roughness variation followed by depth of cut.

$>$ Spindle speed is found to be insignificant on surface roughness.

$>$ The optimal combination of process parameters for minimum surface roughness is obtained at $450 \mathrm{rpm}, 0.09 \mathrm{~mm} / \mathrm{rev}$ feed and $1.0 \mathrm{~mm}$ depth of cut For LUBRICATION Conditions

$>$ The optimal combination of process parameters for minimum surface roughness is obtained at $450 \mathrm{rpm}, 0.09 \mathrm{~mm} / \mathrm{rev}$ feed and $1.0 \mathrm{~mm}$ depth of cut For Dry Condition.

$>$ The ANOVA re related that the percentage contribution of Depth of cut $(70 \%)$ is the dominant parameter followed by Speed (11.6927\%) for surface roughness For LUBRICATION Conditions.

$>$ The ANOVA re related that the percentage contribution of Depth of cut $(44.25 \%)$ is the dominant parameter followed by feed (25.04\%) for surface roughness for dry conditions.

$>$ The average surface roughness values $\mathrm{Ra}$ resulted from machining AISI D3 COLD WORKING steel with CVD coated cemented carbide cutting tools is about 1.64 micro meters For LUBRICATION

$>$ The average surface roughness values $\mathrm{Ra}$ resulted from machining AISI D3 COLD WORKING steel with CVD coated cemented carbide cutting tools is about 1.19 micro meters for DRY.

$>$ The fluctuations of Ra values are explained by the fact that $\mathrm{Ra}$ depends on the turning parameters.

$>$ The regression model was able to predict values for surface roughness with reasonable degree of approximation.
Using the experimental data, a linear regression model is developed and the values obtained for the response $\mathrm{Ra}$ is compared with experimental values. A graph is plotted between regression predicted values and an experimentally measured values.

$>$ It is observed that the predicted values and experimental values of surface roughness are close to each other.

\section{REFERENCES}

1. T. Tamizharasan, J. Kingston Barnabas, "optimization of parameters in hard dry turning using doe, de and pso". The surface finish and flank wear have been investigated in this analysis while machining practically used components.(2012)

2. H.M.Somasekhara, N.lakshamanaswami "optimizing surface roughness in turning operation using Taguchi method and ANOVA", International Journal of Engineering Science and Technology (IJEST), ISSN : 0975-5462 Vol. 4 No.05 May 2012.

3. Hari Singh, pradeep,"optimizing cutting force for turned parts for Taguchi's parameters design approach ", Indian Journal of Engineering \& Materials Sciences, Vol. 12, April 2005, pp. 97-103.

4. Varaprasad Bhemuni, Srinivasa Rao Chelamalasetti, Siva Prasad Kondapalli, "Effect of Machining Parameters on Tool Wear and Nodal Temperature in Hard Turning of AISI D3 Steel", Open Access Library Journal, September 2014, Volume1

5. T. Pravin, C. Somu, R. Rajavel, M. Subramanian, P. Prince Reynold, Integrated Taguchi cum grey relational experimental analysis technique (GREAT) for optimization and material characterization of FSP surface composites on AA6061 aluminium alloys, Materials Today: $\quad$ Proceedings, 2020, https://doi.org/10.1016/j.matpr.2020.02.86 3.

6. R. Ranjith, C. Somu, G. Tharanitharan, Venkatajalapathi.T, Naveenkumar M, Integrated Taguchi cum Grey Relational 
Experimental Analysis (GREAT) for Optimization and Machining Characterization of Cryogenic Cooled AA6063 Aluminium Alloys, Materials Today: Proceedings, Volume 18, Part 7, 2019,Pages 3597- 605, https://doi.org/10.1016/j.matpr.2019.07.29 1.

7. J.S. Durejaa, RupinderSingha \&Manpreet S. Bhattib, "Optimizing flank wear and surface roughness during hard turning of AISI D3 steel by Taguchi and RSM methods", Production \& manufacturing research, an open access journal, Pages 767-783, Published online: 16 Sep 2014.
8. Esmaeil Soltani,Hesam Shahali, "An investigation of surface roughness and main cutting force during the hard turning of AISI d3 tool steel using ceramic tools", research.iaun.ac.ir/pd/es_soltaniold/pdfs/Pa perC_5982.pdf.

9. R.K.Suresh,

P.Venkataramaiah, G.Krishnaiah "Multi response optimization in turning of aisi 8620 alloy steel with CVD tool using DFA and GRA- a comparitive study", Journal of production Engineering, Original Scientific Paper, vol 17, 2014. 